cidents, it was desirable, he thought, that dilatation should be used in its stead in all cases in which this proceeding was practicable. An examination of the statistics of the subject showed that dilatation was impracticable in only about one in every 300 cases. The dilator he employs is like that of Nélaton, except that it has two blades, instead of three. Gradual and slow dilatation of the preputial orifice is practiced, and afterwards daily movement of the prepuce, alternately covering and uncovering the gland.

The other paper by St. Germain was on "Ignipuncture of the Tonsils," which he believes is destined one day to supersede tonsillotomy. It is, he said, a perfectly safe procedure, and therefore much preferable to the latter. By the aid of a Smith's gag a thermo-cautery is introduced into the mouth and inserted into the tonsil to the depth of $\mathrm{I}$ centimetre. The operation is repeated every eight days, and from two to four sittings are required; at the end of which time the tonsil is found to be almost completely shrivelled up. It has proved very successful in St. Germain's hands, and although he has employed it now in a large number of cases no bad results have been noted from it.

Dr. Smith said that he had applied to Dr. A. D. Rockwell, the eminent electro-therapeutist, for an expression of opinion in regard to the advantage and practicability of this procedure, and Dr. Rockwell had written that, although the author's description of the method was too brief and vague to enable one to judge definitely of its merits, the matter seemed plausible and worthy of attention. While the galvano-cautery had the advantage over the knife of giving rise to much less danger of hæmorrhage or pyæmia, its application was too painful and required too long a time (six or eight minutes at a sitting), to be successfully resorted to in the case of young children. Ignipuncture, on the contrary, could no doubt be employed with facility, because its action was in stantaneous.

In the discussion which followed Dr. Smith's address Dr. C. A. Leale suggested the use of bromide of sodium in the place of bromide of potassium in the cerebral irritation of children, as he had found that the former was much less apt to disagree with the stomach than the latter. As to dilatation of the prepuce, this had long been successfully practiced in America, and St. Germain's paper therefore contained nothing that was known here.

Dr. J. R. McGregor said that in regard to whooping-congh he believed that in addition to the primary cause, there was an intense neurosis present, which it was necessary to control in order to deal satisfactorily with the disease. Almost every physician had some favorite remedy, and personally he had obtained the best results with oxalate of serium, which he gave in 5 grain doses once a day; in exceptional cases repeating the dose at night. He could see no great objection to circumcision, and believed that many of the cases in which diphtheria followed it this was due to carelessness on the part of the operator in regard to instruments, etc.

Dr. J. W. S. Gouley said that when the preputial orifice was very narrow it was not safe to attempt retraction, on account of the danger of producing paraphimosis, which was always a serious matter in children. In such cases there was no question in his mind that, as a rule, excision of the prepuce constituted the last treatment. Dilatation, or, more properly, divulsion, was not an easy operation by any means, and the younger the child was the more difficult it was to perform. It could be most satisfactorily accomplished by means of Trousseaux's tracheotomy dilator; but the procedure was always to be condemned when the prepuce was narrow and indurated.

At the close of the discussion Dr. Alfred L. Carroll read a paper entitled "Mineral Water Miracles," in which he gave a forcible exposition, abounding in lively satire, of the ridiculous claims of some of the mineral waters now in vogue; after which Dr. Gouley presented a dermic cyst of the scrotum (the removal of which had also necessitated that of one of the testicles), in which fatty degeneration had been followed by calcareous infiltration, accompanied with the development of a small amount of osscous tissue, the bone-cells being found present under the microscope.

P. B. P.

\section{CYSTOCOLPOCELE COMPLICATING LABOR.}

Dear Sir:-In The Journal of October I5, page 502 , appears the report of a case of labor complicated by cystocolpocele, in which the author says he has found but 37 recorded cases. If of value to the profession, allow me to report the following case :

On September 24,1887 , I was called to attend a case of labor at full term. Labor pains had occurred regularly for the past six hours, though light in character. Upon making a vaginal examination, I found a fluctuating tumor about the size of a fœetal head, depending direct from the superior vaginal wall; the tip of the finger could detect the patulous os, but could not reach the presenting part of the child. The tumor was not painful, nor had there been marked desire to urinate. Patient had passed water several times that day.

I suspected a prolapsed bladder, and requested the patient to urinate, and then found that the obstruction had disappeared, with the exception of the shrunken walls, which lay in rugæ on the upper surface of the vagina. No other trouble was experienced, and in about two hours she was delivered of a fine pair of twins.

This was her fourth accouchement, and in the three preceding ones she had been attended by a midwife; never knew of the prolapse, and had experienced no trouble from it.

Respectfully,

A. J. C. Saunier, M.D.

Libertyville, Ill., Oct. 20, I887.

\section{GLEDITSCHINE-STENOCARPINE}

Dear Sir:-The fact, seemingly well proven by the experience of Drs. Seward, Claiborne, Knapp, Jackson, Mitchell and others, that the newly discovered alkaloid, gleditschine-stenocarpine, is largely 
like cocaine in its power as a local anæsthetic, has prompted me to determine whether it has a value akin to that drug, as a stimulant in the treatment of opium habitués, and I am now experimenting in this direction, using a 2 per cent. solution exclusively by subcutaneous injection. That cocaine, hypodermically, is a valued aid in treating the opium neurosis is beyond question, in my opinion; but it is not a specific, and should never be used for this purpose by the patient himself, be he physician or layman. Should gleditschine have a similar value, it may be found free from the ensnaring danger of cocaine; though, assuming its stimulant power, this freedom from risk will not be likely, and we shall note, probably, in the not far future, baneful effects from its abuse, and gleditschine inebriety be added to the list of toxic neuroses.

It has been stated by Dr. Seward that he "has observed antidotal effects to gleditschine from morphia;" and Mitchell (W. H.) asserts "it is a direct antagonist of morphine and opium, ro drops of the 2 per cent. solution neutralizing $\mathrm{I}$ grain of morphine or 6 of opium." Experiments on rabbits now being made by myself will, it is to be hoped, sustain these claims."

The 2 per cent. solution can be obtained of Messrs. Lehn and Fink, New York City, at a present wholesale cost of $\$ 6$ an ounce. I shall be pleased to receive and report the experience which any reader of THE JouRNAL may have on this subject. Yours very truly,

3I4 State St., Brooklyn, October I5, I887.

\section{BOOK REVIEWS.}

The Physician's Visiting List. (Lindsay \& Blakiston's), Thirty-seventh year. 185 I-1888, with many improvements. Philadelphia: P. Blakiston, Son \& Co.

This visiting list is so well known that no description is needed. Of the various visiting lists it is one of the lightest, strongest, least cumbersome, and most convenient.

Surgery, its Theory and Practice. By William Johnson Walsham, F.R.C.S., Assistant Surgeon to St. Bartholomew's Hospital; Surgeon to the Metropolitan Free Hospital, London, etc. With 236 illustrations. 8vo., pp. ix-655. Philadelphia: P. Blakiston, Son \& Co. 1887. Chicago: W. T. Keener.

While in no sense a "short cut to surgery" Mr. Walsham's book seems to be in the main intended as a manual or handbook for the student and practitioner of surgery. The subjects with which every student ought to be thoroughly acquainted are given special prominence, while the rarer forms of injury and disease have either received but short notice or have been entirely omitted. The details of operative surgery and minor surgery and bandaging, with such other things as the student is sup- posed to be taught practically in the wards, are but briefly discussed.

The first two sections, occupying i I 9 pages, are devoted to "General Pathology of Surgical Diseases," and "General Pathology of Injuries;" for the introduction of which into a manual the author is to be commended. The illustrations, as a rule, are good, in that they show what they are intended to represent. Many of them are new, and we note with pleasure the conspicuous paucity of many too familiar old ones. The book is a good one, and written in Mr. Walsham's well-known lucid style.

\section{MISCELLANEOUS.}

Commemorative Medal, Ninth International MedICAL CONGRESS. - We learn that a contract has been made with a frrst-class medalist connected with the United States Mint at Philadelphia, to engrave and stamp the commemorative medal for the subscribing members of the Ninth International Medical Congress. The work is to be executed in the best possible manner. As several months will be required to prepare the dies, members of the Congress who have not subscribed, we presume can still do so on application to Dr. J. M. Toner, 6I 5 Louisiana Ave., Washington, D. C., who has the matter in charge.

Typhoid Fever in Cincinnati.-Telegraphic dispatches from Cincirnati state there are more than 500 cases of typhoid fever in the City, and that the outbreak of the disease is thought to be due to the condition of the Ohio river, which is much lower than it has been for many years.

Florence Nightingale, the famous heroine of the Crimea, is reported dying at her home in London, from the effects of her perilous labors during the days in which she devoted her life to the care of soldiers wounded in battle.

Dr. JAmes A. Grax, one of the editors of the Atlantic Medical and Surgical Fournal, died on October 7, aged 37 years.

OFFICIAL LIST OF CHANGES IN THE STATIONS AND DUTIES OF OFFICERS SERVING IN THE MEDICAL DEPARTMENT, U. S. ARMY, FROM OCTOBER I5, 1887, TO OCTOBER 21, I887.

Major W. D. Wolverton, Surgeon, detailed as member of Army Retiring Board at Washington, D. C., convened by S. O. 78, A. G. O., April 5, 1887, vice Major C. C. Byrne, Surgeon, hereby relieved. S. O. 241, A. G. O., October 15, 1887 .

Capt. Edwin F. Gardner, Asst. Surgeon, relieved from duty at Ft. Reno, Ind. Ter, and ordered for duty at Ft. Lewis, Col. S. O. 24I, A. G. O., October I 5, I 887 .

Capt. Jno. J. Cochran, Asst. Surgeon, now on duty at the Presidio of San Francisco, Cal., is assigned to temporary duty at hdqrs. Div. of the Pacific, as assistant to the Medical Director of that division. S. O. 244, A. G. O., October 19, 1887.

First Lieut. C. B. Ewing, Asst. Surgeon, granted leave of absence for one month, on surgeon's certificate of disability. S. O. I 12 , Dept. Mo., October I8, I887.

Nathan S. Jarvis, to be Asst. Surgeon, U. S. Army, with the rank of First Lieut., October I 4, I887.

OFFICIAL LIST OF CHANGES IN THE MEDICAL CORPS OF THE U. S. NAVY, DURING THE WEEK ENDING
OCTOBER 22, 1887.

P. A. Surgeon H. G. Beyer, ordered to hold himself in readiness for orders to the "Trenton."

Asst. Surgeon S. S. White, ordered to hold himself in readiness for orders to the "Trenton."

P. A. Surgeon F. B. Stephenson, detached from the "Bache," and ordered to the Navy Yard, Boston.

Asst. Surgeon E. P. Stone, detached from the "New Hampshire," and ordered to the "Bache."

Surgeon T. H. Street, detached from the "Patterson" and placed on waiting orders. 